\title{
Source Attribution of Human Salmonellosis: An Overview of Methods and Estimates
}

\author{
Pires, Sara Monteiro; Vieira, Antonio R.; Hald, Tine; Cole, Dana
}

Published in:

Foodborne Pathogens and Disease

Link to article, DOI:

10.1089/fpd.2014.1744

Publication date:

2014

Document Version

Publisher's PDF, also known as Version of record

Link back to DTU Orbit

\section{Citation (APA):}

Pires, S. M., Vieira, A. R., Hald, T., \& Cole, D. (2014). Source Attribution of Human Salmonellosis: An Overview of Methods and Estimates. Foodborne Pathogens and Disease, 11(9), 667-676.

https://doi.org/10.1089/fpd.2014.1744

\section{General rights}

Copyright and moral rights for the publications made accessible in the public portal are retained by the authors and/or other copyright owners and it is a condition of accessing publications that users recognise and abide by the legal requirements associated with these rights.

- Users may download and print one copy of any publication from the public portal for the purpose of private study or research.

- You may not further distribute the material or use it for any profit-making activity or commercial gain

- You may freely distribute the URL identifying the publication in the public portal 


\title{
Source Attribution of Human Salmonellosis: An Overview of Methods and Estimates
}

\author{
Sara M. Pires, Antonio R. Vieira, ${ }^{2}$ Tine Hald, and Dana Cole ${ }^{2}$
}

\begin{abstract}
Reducing the burden of foodborne salmonellosis is challenging. It requires identification of the most important food sources causing disease and prioritization of effective intervention strategies. For this purpose, a variety of methods to estimate the relative contribution of different sources of Salmonella infections have been applied worldwide. Each has strengths and limitations, and the usefulness of each depends on the public health questions being addressed. In this study, we reviewed the source attribution methods and outcomes of several studies developed in different countries and settings, comparing approaches and regional differences in attribution estimates. Reviewed results suggest that illnesses and outbreaks are most commonly attributed to exposure to contaminated food, and that eggs, broiler chickens, and pigs are among the top sources. Although most source attribution studies do not attribute salmonellosis to produce, outbreak data in several countries suggest that exposure to raw vegetables is also an important source. International travel was also a consistently important exposure in several studies. Still, the relative contribution of specific sources to human salmonellosis varied substantially between studies. Although differences in data inputs, methods, and the point in the food system where attribution was estimated contribute to variability between studies, observed differences also suggest regional differences in the epidemiology of salmonellosis.
\end{abstract}

\section{Introduction}

$\mathbf{S}$ ALMONELLOSIS IS A GROWING public health concern in both the developed and developing worlds. Salmonella spp. have a variety of animal reservoirs and routes of transmission that can result in human infection. However, the majority of infections in developed countries are thought to be caused by foodborne exposures (Scallan et al., 2011). Reducing the burden of foodborne salmonellosis is challenging; it requires identification of the most important food sources causing disease and prioritization of effective intervention strategies. A variety of methods to estimate the relative contribution of different food sources to human foodborne disease have been developed, including the microbial subtyping approach, comparative exposure assessment, epidemiological analysis of sporadic cases, analysis of data from outbreak investigations, and expert elicitation (Pires et al., 2009). Each of these approaches has strengths and limitations, and the usefulness of each depends on the public health questions being addressed. In this study, we reviewed methods and results of several source attribution studies of Salmonella spp. developed in different countries, and compared the approaches and regional differences in the results.

\section{Overview of Source Attribution Methods}

Approaches to source attribution can be grouped broadly into four categories: microbiological, epidemiological, expert elicitation, and intervention studies (Pires et al., 2009). Methods in all categories have been used to estimate the sources of salmonellosis in different subpopulations, and some have applied attribution results beyond the original study population.

One of the most frequently used methods for source attribution of salmonellosis is the microbial subtyping approach. The principle is to compare the subtypes of isolates obtained from different sources (e.g., animals, food) with those isolated from humans. This approach requires characterization of the etiologic agent by subtyping methods (e.g., phenotypic or genotypic subtyping), and depends on strong associations between dominant subtypes and a specific reservoir or source. Using a collection of temporally and spatially related isolates from various sources, this approach estimates the number of laboratory-confirmed, sporadic (i.e., illnesses not associated with outbreaks) human cases attributable to each source; thus, it is facilitated by an integrated foodborne disease surveillance program that collects isolates

\footnotetext{
${ }^{1}$ National Food Institute, Technical University of Denmark, Søborg, Denmark.

${ }^{2}$ Enteric Diseases Epidemiology Branch, Centers for Disease Control and Prevention, Atlanta, Georgia.
} 
from the major food sources, as well as from human cases of infection.

Another microbiological approach to source attribution is the comparative exposure assessment. The principle is to determine the relative importance of the known transmission routes by estimating the human exposure to the hazard via each route. For each known route, this approach requires information on the prevalence and quantity of the hazard in the source, the changes in these throughout the transmission chain, and the frequency of human exposure by each route (e.g., consumption data). With this information, the total exposure in the population associated with each transmission route is estimated. These estimates are used to partition the total number of illnesses caused by the specific hazard to each transmission route, proportionally to the total exposure from all routes. The estimates of exposure for each route can be subsequently combined with a dose-response model to predict the number of infections in the population from each route.

Epidemiological approaches to source attribution include analyses of data from sporadic case-control studies and analyses of information collected during outbreak investigations. Case-control studies of sporadic, laboratory-confirmed infections are the most commonly used approach to determining the importance of possible risk factors for illness, including sources and predisposing, behavioral, or seasonal factors. Population-attributable fractions (PAFs) from case-control studies are used to estimate the proportion of laboratoryconfirmed illnesses in the target population attributable to each source (Greenland and Robins, 1998). A systematic review of published case-control studies of a given hazard can provide an overview of the relevant exposures and risk factors for disease, as well as a summary of estimated PAFs generalized to a broader population. A PAF derived from a metaanalysis of several case-control studies can be combined with an estimate of the total number of illnesses in a population caused by that hazard to estimate the number of illnesses attributable to each exposure.

Many foodborne outbreak investigations are successful in identifying the specific contaminated source or ingredient that transmitted the causative agent. By conducting an analysis of data collected during outbreak investigations, the most common foods involved in outbreaks can be identified. A simple descriptive analysis or summary of outbreak investigations is useful for quantifying the relative contribution of different foods to outbreak illnesses. However, outbreak data have also been used to estimate the total number of illnesses in the population attributable to different foods. The approaches used to extrapolate the results of outbreak investigations to estimate the sources of illness in the population also include methods to estimate the contaminated ingredients in "complex" foods (i.e., foods containing ingredients from different food categories). By assigning a probability to each ingredient corresponding to the likelihood that it was the source of the outbreak, data from both simple (i.e., a single contaminated ingredient or a food containing multiple ingredients belonging to a single food category) and complex foods implicated in outbreaks can be used to attribute foodborne illnesses to sources. A source attribution method using data from both simple and complex foods was developed by Painter et al. (2006, 2013) and adapted by Pires et al. (2010, 2011a, 2012).

Expert opinions may be used to fill data gaps, to combine data from different studies and scientific approaches into a single estimate, or as an alternative source-attribution method when other methods are not feasible or useful to address a public health question (EFSA, 2008). Expert judgments are subjective and may be biased by many factors, including the background and scientific expertise of the respondents. Expert elicitations have also been used to partition the estimated number of foodborne illnesses in the population to foodborne, environmental, contact with animals and their environments, and human-to-human transmission pathways.

The implementation of Salmonella control programs focused on particular foods and the subsequent evaluation of their public health impact on a population constitute largescale intervention studies that can be used to estimate the proportion of illnesses in the population due to those foods. Examples include intervention programs established in Denmark during the 1990s (Wegener et al., 2003) followed by studies that measured reduction of human salmonellosis (Wegener, 2010), and the measures to control the epidemic of Salmonella enterica serotype Enteritidis introduced in the United Kingdom (O'Brien, 2013) followed by an analysis of the decline in human cases.

Each of these methods has different data requirements and may estimate sources for different subpopulations of human illness (i.e., laboratory-confirmed sporadic illnesses, outbreakassociated illnesses, and illnesses in the general population) at different points of the farm-to-consumption chain (production or exposure), and therefore their utility will vary depending on both the hazard and surveillance data available. The variety of methods available for source attribution of foodborne illness has been described in detail by Pires et al. (2009), as well as description of the data requirements of each approach (Pires, 2013).

\section{Overview of Published Studies}

Many source attribution studies for Salmonella spp. using national or regional foodborne disease data have been published in recent years. Several research groups work in this area, including research teams in Denmark, United States, New Zealand, and The Netherlands. We conducted a comprehensive literature review to collect all published studies attributing human salmonellosis to the responsible sources. In addition to a web-based literature search, we have identified published studies referenced in other publications and through personal contacts in the scientific community.

The strengths and weaknesses of each method influence their utility to a specific attribution question, and results should be interpreted in light of these method characteristics (Table 1). Data availability often drives the selection of the source attribution approach used. The microbial subtyping approach has been used in several countries, and it was recently adapted to two sets of data in France to study the impact of data quality on the attribution results (David et al., 2013). In contrast, the comparative exposure assessment approach has only been applied using data from Denmark (Pires, 2009). Table 2 provides an overview of the country or region of origin and methods used in recently published studies. We present, compare, and discuss the main findings of these studies.

\section{Microbial subtyping}

The microbial subtyping approach originally described by Hald et al. (2004) is routinely applied in Denmark to estimate 
Table 1. Strengths and Limitations of Source Attribution (SA) Methods

\begin{tabular}{|c|c|c|}
\hline SA approach & Strengths & Limitations \\
\hline \multicolumn{3}{|l|}{ Subtyping approaches } \\
\hline Microbial subtyping & $\begin{array}{l}\text { Identifies the most important reservoirs } \\
\text { of the zoonotic agent, and therefore: } \\
\text { is useful to prioritize interventions } \\
\text { at production level. } \\
\text { reduces uncertainty due to } \\
\text { cross-contamination and the risk of } \\
\text { attributing to an "accidental" } \\
\text { source. } \\
\text { is able to follow trends over time. }\end{array}$ & $\begin{array}{l}\text { Limited to pathogens that are } \\
\text { heterogeneously distributed among the } \\
\text { reservoirs. } \\
\text { No information on different transmission } \\
\text { pathways from reservoirs to humans. } \\
\text { Data intensive, requiring a collection of } \\
\text { representative isolates from all (major) } \\
\text { sources. } \\
\text { Standardized subtyping methods with } \\
\text { appropriate level of discrimination are } \\
\text { required (methods are changing over } \\
\text { time, and new methods are potentially } \\
\text { too discriminatory for SA models). }\end{array}$ \\
\hline $\begin{array}{l}\text { Comparative exposure } \\
\text { assessment }\end{array}$ & $\begin{array}{l}\text { Attributes illness to sources taking into } \\
\text { account the different transmission } \\
\text { routes from the same reservoir. } \\
\text { Once a model is developed, new data can } \\
\text { be easily included. }\end{array}$ & $\begin{array}{l}\text { Often limited by lack of data, which } \\
\text { results in large uncertainties around the } \\
\text { estimates. }\end{array}$ \\
\hline \multicolumn{3}{|l|}{ Epidemiological studies } \\
\hline $\begin{array}{l}\text { Case-control studies } \\
\text { (including systematic } \\
\text { review) }\end{array}$ & $\begin{array}{l}\text { Valuable tool to identify relevant risk } \\
\text { factors for human infections, including } \\
\text { sources of exposure, predisposing, } \\
\text { behavioral or seasonal factors. } \\
\text { A systematic review of published case- } \\
\text { control studies can provide an overview } \\
\text { of the relevant exposures and risk } \\
\text { factors for that infection, and may } \\
\text { detect temporal and geographical } \\
\text { variations. } \\
\text { Can identify a wide range of known and } \\
\text { unknown risk factors. }\end{array}$ & $\begin{array}{l}\text { Misclassification due to immunity may } \\
\text { reduce attributable risk or even suggest } \\
\text { protection. } \\
\text { Most studies only explain a small fraction } \\
\text { of all cases. } \\
\text { Cases may reflect a mixture of possible } \\
\text { sources of exposure, and it may be } \\
\text { difficult to distinguish between these } \\
\text { exposures. } \\
\text { Statistical power to determine the } \\
\text { importance of common exposures often } \\
\text { requires enrollment of many } \\
\text { participants. } \\
\text { Misclassification of exposures due to lack } \\
\text { of accuracy of recall may lead to an } \\
\text { underestimation of the burden of illness } \\
\text { attributed to specific exposures. }\end{array}$ \\
\hline $\begin{array}{l}\text { Analysis of data from } \\
\text { outbreaks }\end{array}$ & $\begin{array}{l}\text { Documentation that a specific pathogen } \\
\text { was transmitted to humans via a } \\
\text { specific food item can be available. } \\
\text { Data may capture the effect of } \\
\text { contamination at multiple points from } \\
\text { the farm-to-consumption chain } \\
\text { A wide variety of food vehicles are } \\
\text { represented, including less frequently } \\
\text { identified food items. } \\
\text { Data from outbreak investigations may be } \\
\text { the most readily available source of } \\
\text { information for source attribution in } \\
\text { some countries or regions. }\end{array}$ & $\begin{array}{l}\text { Quality of evidence varies and food } \\
\text { classification schemes are not } \\
\text { harmonized. } \\
\text { Large outbreaks, outbreaks associated } \\
\text { with point sources, outbreaks that have } \\
\text { short incubation periods, and outbreaks } \\
\text { that cause serious illness are more } \\
\text { likely to be investigated. } \\
\text { Illnesses included in data from outbreak } \\
\text { investigations may not be } \\
\text { representative of all foodborne } \\
\text { illnesses. } \\
\text { Certain food vehicles are more likely to } \\
\text { be associated with reported outbreaks } \\
\text { than others, which can lead to an } \\
\text { overestimation of the proportion of } \\
\text { human illnesses attributed to a specific } \\
\text { food. }\end{array}$ \\
\hline Intervention studies & $\begin{array}{l}\text { Allows for a direct measure of the impact } \\
\text { of a given source on the number of } \\
\text { human cases of infection, avoiding the } \\
\text { account for the effect of external } \\
\text { sources or risk factors. }\end{array}$ & $\begin{array}{l}\text { Interpretation of data from "large-scale" } \\
\text { interventions is difficult, since usually } \\
\text { several interventions are implemented } \\
\text { at the same time. } \\
\text { Complex and resource demanding studies. }\end{array}$ \\
\hline Expert elicitations & $\begin{array}{l}\text { Useful tool when data are lacking. } \\
\text { For some pathogens, may be the only } \\
\text { available method for SA. }\end{array}$ & $\begin{array}{l}\text { Conclusions are based on the individual } \\
\text { experts' judgment, which may be } \\
\text { misinformed or biased. }\end{array}$ \\
\hline
\end{tabular}




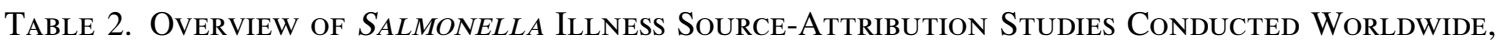
By Source Attribution Method

\begin{tabular}{|c|c|c|c|c|c|c|}
\hline Country/region & $\begin{array}{l}\text { Microbial } \\
\text { subtyping }\end{array}$ & $\begin{array}{l}\text { Analyses of } \\
\text { outbreak data }\end{array}$ & $\begin{array}{l}\text { Expert } \\
\text { elicitation }\end{array}$ & $\begin{array}{l}\text { Comparative } \\
\text { exposure } \\
\text { assessment }\end{array}$ & $\begin{array}{c}\text { Systematic review } \\
\text { of case-control } \\
\text { studies }\end{array}$ & References \\
\hline Denmark & $X$ & & & $\mathrm{X}$ & & $\begin{array}{l}\text { Hald et al. (2004) } \\
\text { Pires (2009) }\end{array}$ \\
\hline Sweden & $\mathrm{X}$ & & & & & Whalström et al. (2011) \\
\hline The Netherlands & $\mathrm{X}$ & & $\mathrm{X}$ & & & $\begin{array}{l}\text { Valkenburgh et al. (2007) } \\
\text { Havelaar et al. (2008) }\end{array}$ \\
\hline European Union & $\mathrm{X}$ & $\mathrm{X}$ & & & & Pires et al. (2011a) \\
\hline $\begin{array}{l}\text { Latin America } \\
\text { and Caribbean }\end{array}$ & & $\mathrm{X}$ & & & & Pires et al. (2012) \\
\hline United States & $\mathrm{X}$ & $\mathrm{X}$ & $\mathrm{X}$ & & & $\begin{array}{l}\text { Guo et al. }(2011) \\
\text { Painter et al. }(2013) \\
\text { Gould et al. }(2013) \\
\text { Hoffman et al. }(2007)\end{array}$ \\
\hline Canada & & $\mathrm{X}$ & $\mathrm{X}$ & & & $\begin{array}{l}\text { Ravel et al. (2009) } \\
\text { Ravel et al. (2010) }\end{array}$ \\
\hline Japan & $\mathrm{X}$ & $\mathrm{X}$ & & & & $\begin{array}{l}\text { Toyofuku et al. (2011) } \\
\text { Pires et al. (2011b) }\end{array}$ \\
\hline New Zealand & $\mathrm{X}$ & $\mathrm{X}$ & $\mathrm{X}$ & & & $\begin{array}{l}\text { Mullner et al. (2009) } \\
\text { King et al. }(2011) \\
\text { Lake et al. }(2010)\end{array}$ \\
\hline Global & & & & & $\mathrm{X}$ & Domingues et al. (2012) \\
\hline
\end{tabular}

${ }^{\mathrm{a}}$ Several case-control studies of sporadic Salmonella infections have been published.

Table 3. Estimated Percentage of Salmonella Illnesses Attributable to Animal-Food Sources, Travel, Wildlife, Unknown Sources, and Outbreaks in Denmark, Sweden, the European Union* (EU), the United States (USA), New Zealand, and Japan Using a Microbial Subtyping Approach

\begin{tabular}{|c|c|c|c|c|c|c|c|c|c|c|}
\hline & Denmark $^{\mathrm{a}}$ & Sweden $^{\mathrm{b}}$ & $E U^{\mathrm{c}}$ & $\begin{array}{c}\text { EU } \\
\text { Eastern }^{\mathrm{c}, *}\end{array}$ & $\begin{array}{c}\text { EU } \\
\text { Northern }{ }^{\mathrm{c}, *}\end{array}$ & $\begin{array}{c}E U \\
\text { Western }{ }^{\mathrm{c}, *}\end{array}$ & $\begin{array}{c}E U \\
\text { Southern }\end{array}$ & $U S A^{\mathrm{d}, \dagger}$ & $\begin{array}{c}\text { New } \\
\text { Zealand }\end{array}$ & $\operatorname{Japan}^{\mathrm{f}, \mathrm{t}}$ \\
\hline Pigs & 15.1 & 0.08 & 26.9 & 22.7 & 10.6 & 34.1 & 43.6 & $<1$ & 60 & 5.3 \\
\hline Cattle & 0.7 & 0.1 & - & - & - & - & - & $29^{*, \mathrm{a}}$ & 11.5 & 0.5 \\
\hline Layers & 1.8 & 0.16 & 43.8 & 59.4 & 30 & 41.8 & 28.4 & $6^{*, \mathrm{~b}}$ & 3.2 & 63.3 \\
\hline Broilers & 0.5 & 0.09 & 3.4 & 7.0 & 1.2 & 2.1 & 3.1 & 48 & 21.2 & 6.4 \\
\hline Ducks & 0.1 & - & - & - & - & - & - & - & - & - \\
\hline Turkeys & - & - & 4.0 & 2.2 & 7.4 & 4.1 & 7.6 & 17 & - & - \\
\hline Lamb/mutton & - & - & - & - & - & - & - & - & 1.4 & - \\
\hline Imported food & - & 6.4 & - & - & - & - & - & - & - & - \\
\hline Pork & 5.4 & - & - & - & - & - & - & - & - & - \\
\hline Beef & 2.0 & - & - & - & - & - & - & - & - & - \\
\hline Poultry & 2.5 & - & - & - & - & - & - & - & - & - \\
\hline Wildlife & - & 0.6 & - & - & - & - & - & - & - & - \\
\hline Travel & 46.9 & 82 & 9.2 & 0.8 & 34.5 & 4.8 & 0.7 & - & — $^{*, \mathrm{c}}$ & - \\
\hline $\begin{array}{l}\text { Unknown, outbreak- } \\
\text { associated }\end{array}$ & 5.1 & 2.9 & 3.6 & 5.4 & 4.0 & 2.2 & 4.2 & - & - & - \\
\hline Unknown, sporadic & 19.8 & 7.7 & 9.0 & 2.5 & 12.4 & 10.9 & 12.5 & - & - & 20.8 \\
\hline
\end{tabular}

*EU regions as defined by the United Nations. Eastern Europe: Czech Republic, Hungary, Poland, and Slovakia. Northern Europe: Denmark, Estonia, Finland, Ireland, Latvia, Lithuania, Sweden, and the United Kingdom. Southern Europe: Cyprus, Greece, Italy, Portugal, Slovenia, and Spain. Western Europe: Austria, Belgium, France, Germany, Luxembourg, and the Netherlands.

${ }^{\mathrm{a}}$ Data from 2010, Anon., 2011; ${ }^{\mathrm{b}}$ Data from 2004-2006, Whalström et al., 2011; ${ }^{\mathrm{c}}$ Data from 2007-2009, Pires et al., 2011a; ${ }^{\mathrm{d}} \mathrm{Guo}$ et al., 2011; ${ }^{\mathrm{e}}$ Mullner et al., 2009; ${ }^{\mathrm{f}}$ Toyofuku et al., 2011.

Estimates are restricted to those infections estimated to be domestically acquired and sporadic.

Median of estimates over 10 years (1998-2017).

",asum of estimates for "ground beef" and "intact beef".

*,b Estimate for "egg products" other than intact shell eggs.

\#Source not included in model.

${ }^{*}, \mathrm{c}$ Estimates are restricted to those infections estimated to be domestically acquired. 
the relative contribution of domestic and imported foodanimal sources to sporadic salmonellosis. The proportion of cases acquired abroad is also estimated, as is the proportion of disease that cannot be attributed to any of the known sources (Anon., 2011). Results from 2010 estimated that domestically produced pork was the food most likely to cause illness in the country $(15 \%)$, followed by imported pork (5\%), imported beef (2\%), and table eggs (2\%) (Table 3). Nearly half of the reported Salmonella infections (47\%) were estimated to be acquired during international travel. When the same model was applied to data from Sweden (Whalström et al., 2011), results indicated that over $80 \%$ of the Salmonella cases were acquired abroad and that domestic food-producing animals were responsible for less than $1 \%$ (Table 3 ).

The Hald approach was also applied to data from several European Union (EU) countries in a model that used data from the European Center for Disease Control and the European Food Safety Authority (EFSA) (Pires et al., 2011a). The model was applied to data from 24 Member States and attributed human sporadic salmonellosis to four animal reservoirs: pigs, broiler chickens, laying hens, and turkeys. Results showed that the relative contribution of sources varied between regions and countries (Table 3). In contrast to independent results from Denmark, this model estimated that in the EU the laying hen reservoir (eggs) was the most important source ( $44 \%$ of cases), followed by pigs (27\%). This was driven by results of analyses for Eastern, Northern, and Southern Europe, where layers contributed between $30 \%$ and $59 \%$ of salmonellosis. Results for food sources of disease among Western EU states were more similar to those from Denmark, with pork being the leading food source (44\%), and turkeys (4\%) and broilers (3\%) less important. The estimated contribution of broilers was low, representing less than $1 \%$ of the total reported Salmonella cases in Denmark and Sweden, and around 3\% in EU countries overall (Table 3). International travel was a less important source of salmonellosis in the EU overall (9\%) than in Northern EU (which includes Denmark and Sweden), where it was responsible for an estimated 33\% of infections. Overall, $4 \%$ of reported illnesses were related to outbreaks with unknown source, and $9 \%$ of the cases could not be attributed to any source included in the model (Table 3 ).

The Hald microbial subtyping model (Hald et al., 2004) was also adapted to national surveillance data from Japan, the United States, and New Zealand. In Japan, data collected between 1998 and 2007 was used to estimate the number of human Salmonella illnesses attributable to each of the major food animal reservoirs (Toyofuku et al., 2011). Eggs were estimated to be the most important source, responsible for over $50 \%$ of cases in most years. Broilers and pigs were the second most important sources, depending on the year, while cattle were seldom associated. The U.S. model adaptation (Guo et al., 2011) estimated the relative proportions of domestically acquired sporadic Salmonella infections resulting from contamination in six food sources sampled at processing sites in the United States from 1998 through 2003. Unlike results from the EU analysis, broilers were estimated to be the most important food source of domestic sporadic cases of salmonellosis (48\%) for all study years. Additional sources were ground beef $(28 \%)$, turkey (17\%), egg products other than intact shell eggs $(6 \%)$, intact beef $(1 \%)$, and pork $(<1 \%)$. However, lacking data from other sources, the U.S. model estimated that all Salmonella illnesses were associated with the six modeled food sources, and did not attribute any illnesses to travel, shell eggs, produce, or other sources. The New Zealand model included several modifications that allow it to be more easily adapted to countries without intensive surveillance systems (Mullner et al., 2009). The model attributed the majority of the Salmonella illnesses to pork (60\%), followed by poultry (21\%) and beef and veal (12\%); eggs $(3 \%)$ and lamb (1\%) were estimated to be minor sources.

\section{Analysis of data from outbreak investigations}

Statistical analyses of outbreak data have been used in several countries to attribute illnesses to sources and examine changes in the foods causing outbreaks over time. A statistical analysis of data from Salmonella outbreaks in Canada from 1996 to 2005 (Ravel et al., 2009) showed that produce was the most frequent cause of outbreaks (29\%), followed by poultry (15\%), other meats $(15 \%)$, dairy products $(9 \%)$, and seafood $(6.6 \%)$. In contrast to findings in other regions, attribution to eggs was low, causing only $5 \%$ of outbreaks. In $13 \%$ of outbreaks, the implicated food was "complex," and the contaminated ingredient was not identified or estimated through modeling.

In another study, outbreaks of salmonellosis reported in New Zealand from 2000 to 2009 were analyzed (King et al., 2011). The study included an analysis of outbreak settings, main transmission pathway, and food sources. Foodborne transmission was reported for $63 \%$ of the 123 outbreaks for which only 1 mode of transmission was reported, followed by person-to-person (32\%), waterborne (3\%), and zoonotic (2\%). The results of this analysis support the hypothesis that salmonellosis is primarily a foodborne disease in New Zealand, but the study did not identify important food vehicles.

A similar analysis of Salmonella outbreaks was conducted in Latin America and the Caribbean (Pires et al., 2012). Data from 20 countries for the period 1993 through 2010 were collected. Overall, eggs, meat products, vegetables, chicken, grains and beans, and pork were the most important sources of salmonellosis. When outbreaks with an unknown source were excluded, results showed a substantial increase from the 1990s to the 2000s in the proportion of illnesses attributed to eggs (from 17\% to $43 \%$ ) and pork $(4 \%-9 \%)$, and minor increases in the relative contribution of vegetables $(10 \%-12 \%)$. In contrast, the proportion of illnesses attributed to meat products (29\%-9\%) and chicken $(12 \%-6 \%)$ decreased in the same period. The method was also applied to obtain source attribution estimates for Japan (Pires et al., 2011b). Data included the study period 20002009 and also attributed disease to both food sources and water. Estimates suggested that eggs were the most important food source, and that the proportion of illnesses attributed to this source increased in the second half of the decade. Among illnesses attributed to a known source, vegetables followed eggs in importance, contributing $13 \%$ of illnesses from 2000 to 2004 and $17 \%$ from 2005 to 2009 , followed by grains and beans (12\% from 2000 to 2004 and 12.4 from 2005 to 2009). All remaining food sources were of minor importance. However, over $80 \%$ of reported outbreaks did not implicate a contaminated source, and therefore could not be used in the model.

A statistical analysis of outbreak data collected in the United States was conducted to determine significant changes over time in the proportion of outbreaks and outbreak 
Table 4. Percentage of Estimated Number of $S_{A} L M o n e l l a$ Infections Attributed to Food Sources in European Union Regions, Japan, and the United States, as Estimated by Analyses OF OUTBREAKS WITH KNOWN SOURCES

\begin{tabular}{|c|c|c|c|c|c|c|c|}
\hline & \multicolumn{4}{|c|}{ Europe } & & & \multirow[b]{2}{*}{$U S A^{\mathrm{c}}$} \\
\hline & \multicolumn{4}{|c|}{$2007-2009^{\mathrm{a}, \mathrm{d}}$} & \multicolumn{2}{|c|}{ Japan $^{\mathrm{b}, \mathrm{d}}$} & \\
\hline & $E E$ & $N E$ & $S E$ & $W E$ & 2000-2004 & 2005-2009 & 1998-2008 \\
\hline Eggs & 84.3 & 40.0 & 73.8 & 62.1 & 57.2 & 49.6 & 14.8 \\
\hline Dairy & 2.7 & 7.1 & 1.5 & 4.0 & 0.5 & 0.4 & 7.2 \\
\hline Goat milk & 0.0 & 0.0 & 0.0 & 0.0 & 0.0 & 0.0 & - \\
\hline Meat & 1.8 & 3.0 & 2.1 & 4.4 & 0.1 & 0.4 & - \\
\hline Poultry & 0.0 & 0.0 & 13.7 & 0.3 & 0.0 & 0.0 & 19.0 \\
\hline Chicken & 4.1 & 11.8 & 2.1 & 4.0 & 5.3 & 6.4 & - \\
\hline Ducks & 0.0 & 0.0 & 0.0 & 0.0 & 0.3 & 0.8 & - \\
\hline Turkey & 0.3 & 1.6 & 0.0 & 0.7 & 0.0 & 0.0 & - \\
\hline Beef & 0.7 & 0.2 & 0.4 & 1.4 & 2.0 & 0.8 & 7.3 \\
\hline Pork & 2.4 & 14.0 & 0.0 & 16.6 & 2.0 & 1.2 & 6.2 \\
\hline Other meat & 0.0 & 0.0 & 0.0 & 0.0 & 0.0 & 0.0 & - \\
\hline Lamb & 0.0 & 0.0 & 0.0 & 0.3 & 0.0 & 0.0 & - \\
\hline Mutton & 0.0 & 0.0 & 0.0 & 0.0 & 0.0 & 0.0 & - \\
\hline Horse & - & - & - & - & 0.0 & 0.0 & - \\
\hline Game & 0.0 & 0.0 & 0.0 & 0.0 & 0.3 & 0.8 & $0.4^{\mathrm{e}}$ \\
\hline Fruits and nuts & 0.0 & 1.6 & 0.0 & 0.5 & 0.7 & 0.4 & 13.0 \\
\hline Vegetables & 0.6 & 18.5 & 1.4 & 2.1 & 13.2 & 16.8 & - \\
\hline Vine & - & - & - & - & - & - & 20.7 \\
\hline Sprout & - & - & - & - & - & - & 3.1 \\
\hline Leafy & - & - & - & - & - & - & 2.9 \\
\hline Root & - & - & - & - & - & - & 1.2 \\
\hline Grains and beans & 1.3 & 1.0 & 0.5 & 0.7 & 11.8 & 12.4 & 2.9 \\
\hline Oils and sugar & 1.7 & 0.2 & 0.1 & 0.7 & 0.7 & 0.8 & 0.0 \\
\hline Seafood & 0.3 & 1.2 & 3.8 & 2.3 & 0.0 & 0.0 & - \\
\hline Mollusk & - & - & - & - & - & - & 0.2 \\
\hline Crustacean & - & - & - & - & - & - & 0.2 \\
\hline Shellfish & - & - & - & - & 2.0 & 2.8 & - \\
\hline Finfish & - & - & - & - & 3.3 & 5.6 & 0.7 \\
\hline Seaweed & - & - & - & - & 0.5 & 0.2 & - \\
\hline Fungus & - & - & - & - & - & - & 0.1 \\
\hline Water & 0.0 & 0.0 & 1.0 & $\overline{0.0}$ & 0.3 & $\overline{0.4}$ & - \\
\hline Other & - & - & - & - & - & - & - \\
\hline
\end{tabular}

${ }^{\mathrm{a}}$ Pires et al., 2011a; ${ }^{\mathrm{b}}$ Pires et al., 2011b; ${ }^{\mathrm{c}}$ Painter et al., 2013.

${ }^{\mathrm{d}}$ Illness was attributed to different hierarchical levels of the food categorization tree, on the basis of available data. Attribution to a given level (e.g., chicken) is not counted at another level in the same branch (e.g., poultry).

e Includes lamb and mutton.

EE, Eastern Europe; NE, Northern Europe; SE, Southern Europe; WE, Western Europe.

illnesses attributable to each food category using information from outbreaks implicating simple foods (Gould et al., 2013). In this analysis, Salmonella outbreaks were most commonly associated with poultry (includes both chicken and turkey; $30 \%$ ) and eggs (24\%). Other food categories showed much lower attribution proportions: pork at $9 \%$ and beef at $8 \%$. Although changes in the proportions of outbreaks associated with eggs, poultry, beef, pork, and vine-stalk vegetables were observed, only the change associated with the proportion attributed to eggs was statistically significant, decreasing from $33 \%$ in 1998-1999 to $15 \%$ in 2006-2008.

Probabilistic models using information from both simple and complex foods implicated in outbreaks have been applied in several countries and regions to attribute the estimated number of Salmonella infections in the population to food sources (Table 4). Such a model was applied to data from 27
EU Member States, Norway, and Switzerland. It attributed all Salmonella illnesses, both sporadic and outbreak-associated, occurring between 2007 and 2009 to water and 19 food sources based on the attribution proportions estimated from outbreaks with known sources (Table 4) (Pires et al., 2011a). Eggs were estimated to be the most important source, followed by pork, chicken, the general category "meat and poultry," and dairy products. The proportion of Salmonella outbreaks attributed to an unknown source and to various food sources varied substantially among EU regions (Table 4). A higher proportion of illnesses were attributed to eggs in Eastern Europe (84\%) and Southern Europe (74\%) than in other regions. Pork followed eggs in importance in Western Europe (17\%), whereas vegetables were estimated to be a major contributor in Northern Europe (19\%). Chicken (ranking second to fourth, depending on region) and dairy 
products (ranking third to fifth, depending on region) were important in all regions.

Using a similar approach, outbreak data collected by the U.S. Centers for Disease Control and Prevention (CDC) Foodborne Disease Outbreak Surveillance System from 1998 through 2008 was used in a recently published source attribution study (Painter et al., 2013). The model used data on the number of illnesses associated with outbreaks implicating either a simple or complex food in a probabilistic model attributing the estimated number of domestically acquired foodborne Salmonella illnesses (Scallan et al., 2011) to food categories. In this analysis, vine-stalk vegetables and poultry (includes both chicken and turkey) were estimated to be the most common sources, responsible for $21 \%$ and $19 \%$ of illnesses, respectively (Table 4). These were followed by eggs $(15 \%)$ and the fruits and nuts category (13\%).

\section{Systematic review of case-control studies}

To identify the most important risk factors for sporadic cases of salmonellosis, a systematic review of case-control studies and a meta-analysis of study results was performed (Domingues et al., 2012). Thirty-five Salmonella casecontrol studies published in 11 countries were identified (Australia, Canada, Denmark, France, the Netherlands, Norway, Spain, Switzerland, Trinidad and Tobago, United States, and United Kingdom). Results showed that international travel, medical predispositions (i.e., intake of antiacids, pre-existing medical condition, and previous intake of antimicrobials), eating raw eggs, and eating in a restaurant were the most important risk factors for sporadic human salmonellosis. Consumption of undercooked or raw eggs and chicken in a restaurant were the only food items identified as exposure risks for human disease in the analysis; environmental routes (both drinking and recreational waters), direct contact with pets and farm animals, and various predisposition factors proved to play major roles in human salmonellosis. The results of the analyses focusing on serotypes suggested that traveling abroad and consumption of eggs are particularly important risk factors for Salmonella enterica serotype Enteritidis infection, while previous intake of antimicrobials was the only risk factor identified for Typhimurium. The studies did not allow for an analysis by region or age group.

\section{Expert elicitation}

Expert elicitations have estimated the proportion of all Salmonella illnesses in the population that can be attributed to foodborne transmission. In 1999, Mead et al. partially relied on expert opinions to estimate that $95 \%$ of U.S. salmonellosis was foodborne (Mead et al., 1999). Later estimates of the total number of foodborne illness in the United States published by Scallan et al. (2011) were similar, with $94 \%$ of domestically acquired salmonellosis estimated to be foodborne. Hall and Kirk performed an expert elicitation with experts from public health and food safety fields in Australia, where $87 \%$ of the Salmonella illnesses cases were attributed to foodborne sources (Hall and Kirk, 2005). Estimates of foodborne transmission of Salmonella in New Zealand based on expert elicitation were much lower, with a most likely value of $61 \%$ (Cressey and Lake, 2005).

An expert elicitation study was conducted to estimate the fractions of several causes of enteric illness transmitted by five major pathways globally (food, environment, direct contact, human-to-human transmission, and travel) and by 11 foods (Havelaar et al., 2008). The study estimated that, for Salmonella, 55\% of cases are foodborne and that eggs are the most important food source (22\%), followed by poultry (15\%), pork (14\%) and beef and lamb (13\%). Another expert elicitation study performed by Hoffmann et al. (2007) in the United States used 45 experts, including leading food safety scientists, public health officials, and policy experts. Results suggested that $35 \%$ of U.S. foodborne Salmonella illnesses can be attributed to poultry, $22 \%$ to eggs, $12 \%$ to produce and $11 \%$ to beef. An expert elicitation conducted in Canada showed that, among Salmonella illnesses transmitted through food, poultry $(34 \%-42 \%)$, eggs $(19 \%-21 \%)$, produce $(8 \%-$ $18 \%$ ), and pork (7\%-8\%) were the main sources (Davidson et al., 2011). The initial results of the Canadian expert elicitation were widely diverse. Because disagreements between experts clustered in two distinct subgroups for certain pathogens, the authors used external information to choose the estimates derived from one subgroup of experts. Because of differences in the selection of experts, the elicitation tool, and the analysis of results, comparison of results from different expert elicitations should be made with care.

\section{Discussion}

Salmonellosis is a leading bacterial cause of foodborne illness in many developed countries. To inform prevention strategies, several approaches to source attribution have been applied to data collected in several countries. The results of these studies suggest that illnesses and outbreaks are most commonly attributed to food exposures, and eggs and broiler chickens are among the top food sources. Although most types of source attribution studies do not attribute Salmonella infections to produce commodities, studies using outbreak data in several countries suggest that produce is also a significant source. Attribution to international travel is also consistent among studies, but none provided specific information regarding countries associated with higher infection risks. Other studies have analyzed available data on human salmonellosis acquired during international travel (Ekdahl et al., 2005; Havelaar et al., 2012; Kendall et al., 2012), but these data have not been used to attribute salmonellosis to different countries or regions.

Each approach to source attribution has different data requirements and method uncertainties, and attributes illness from different subpopulations to various points of the farmto-consumption chain. These differences in data and methods contribute to the observed variability in estimates across the studies. Nonetheless, comparisons of the relative contribution of different foods and transmission pathways among different countries highlight regional differences in the epidemiology of salmonellosis.

Estimates of source attribution will vary depending upon the approach used. Case-control studies of sporadic illnesses and analyses of outbreak data both attribute illnesses to contamination at the point of consumption or the point of direct contact. However, case-control studies estimate attributable fractions by comparing the exposure distributions among sporadic cases and population-based controls after controlling for potentially confounding variables and estimating the excess risk associated with specific exposures. 
While attribution estimates for a range of food and nonfood exposures in the population can be obtained using casecontrol studies, the population-attributable fractions from these studies reflect the results of statistical models and are prone to limitations such as recall bias and reliance on several assumptions (Levine, 2007). In contrast, outbreak investigations directly determine the causal transmission route of illnesses, but these data can only attribute to exposures causing multiple illnesses clustered in time, in a single exposure location, or linked by the same etiologic agent subtype. As a result, attributable fractions obtained from case-control studies represent very different measures from those determined by outbreak analyses, and assumptions are required to generalize estimates from outbreak data to nonoutbreak-related illnesses in the population. Microbial subtyping methods have also been used to attribute both sporadic and outbreak illnesses to sources. Attributable fractions determined by microbial subtyping analyses are based on variations in food contamination, and so represent very different measures from those determined by analyses of outbreaks or case-control studies. Assessing the degree to which estimates using these three data sources (outbreaks, case-control studies, and microbial subtypes of isolates from sources and ill persons) vary can help investigators determine data gaps and methods to improve estimates. However, analyses using data obtained from differing points in the farm-to-table continuum would be expected to produce different estimates.

The microbial subtyping approach requires estimates of Salmonella prevalence in all possible sources of human infection at the point of attribution for assumptions associated with this approach to be valid. All but the U.S. and New Zealand microbial subtyping models included a category "unknown" to account for sources of salmonellosis not specified in the model; in these two countries, all domestically acquired infections were assumed to be foodborne. Likewise, variation in the food regulatory and surveillance systems between countries also contributes to differences in the inherent model assumptions associated with the point in the food chain where source attribution estimates are derived. For example, in Sweden Salmonella surveillance in food animals includes regular sampling of production animals. Consequently, use of these subtyping models includes the assumption that all human infections are attributable to these farm sources, either directly through contact with farm animals or their food products, or indirectly via contamination of the environment or cross-contamination of other foods. In contrast, in the United States, regulation and collection of surveillance data on meat products is primarily at the point of slaughter and processing, so attribution to only this point in the food production chain includes the assumption that all infections result from exposure to animal food products or foods cross-contaminated by animal food products. Sampling strategies also vary among surveillance systems, depending upon the goals of the program. Thus, variation in food surveillance programs contributes to differences between countries to reliably estimate contamination prevalence among different sources. Baseline surveys of food animal sources conducted in the EU and the United States contributed prevalence data to subtyping models. Likewise, routine surveillance of production animals conducted in Sweden and other countries also provide good prevalence estimates. However, many countries conduct risk-based sampling, targeting sur- veillance to farms and facilities where contamination is most likely, and in these countries adaptations to the model are needed as was done in the United States, Japan, and New Zealand. These differences in data sources and modeling methods also limit direct comparisons of attribution estimates across studies using similar approaches but data from different sources.

Country-specific differences in human surveillance systems also contribute to data-dependent variability in attribution estimates. Detection and reporting of human Salmonella infection is dependent upon healthcare and public health infrastructures, health-seeking behavior in the populations under surveillance, and diagnostic laboratory systems. These differences can bias human data available for attribution. For example, health-seeking behavior and laboratory testing practices may cause surveillance data to be over-representative of more susceptible populations such as the young, elderly, and those with chronic conditions (Scallan et al., 2006). The degree to which these populations are over-represented may vary globally across cultures and levels of access to healthcare. In addition, differences in outbreak surveillance and reporting practices can also contribute to variability in the results of attribution analyses. Not all countries routinely collect data for nonfoodborne outbreaks. In 2009, the United States expanded national surveillance capacity to collect data on nonfoodborne outbreaks, resulting in a lower proportion of Salmonella outbreaks being attributed to food sources than previously estimated (Hall et al., 2013). Likewise, criteria for outbreak reporting can vary between reporting jurisdictions. In some regions, outbreaks are more likely to be reported when a specific contaminated source is confirmed by isolation of the pathogen or agent in the food, while other public health agencies may report all outbreaks investigated, regardless of the level of certainty associated with the transmission pathway or implicated source. In regions or countries where these types of surveillance bias are prevalent, attribution studies may overestimate the importance of sources associated with susceptible subpopulations or transmission pathways more likely to lead to identification of a contaminated source.

In addition to method- and data-dependent sources of variability, attribution estimates reflect underlying differences in the epidemiology of salmonellosis in different countries and regions. For example, there were several differences in the observed distributions of Salmonella subtypes in food sources among EU countries (EFSA, 2008); and serotype Heidelberg was among the top four subtypes causing U.S. illnesses, but was not among the top 10 in the EU study (EFSA, 2008; Guo et al., 2011). Likewise, differences in human consumption, international travel, and contact with water and animals play a role in the importance of specific sources of salmonellosis among different countries or regions. In the microbial subtyping model of Denmark, pork was the most commonly consumed food, whereas chicken was most commonly consumed in the U.S. model (Hald et al., 2004; Guo et al., 2011). Several studies found international travel to be a significant source of Salmonella infection. Collection of data on the country or region visited by ill persons can provide information on relative risks of travel to those regions (Kendall et al., 2012; Ekdahl et al., 2005).

In spite of the limitations in comparing source attribution estimates derived from different studies and countries, there 
are relevant observations regarding common sources of salmonellosis globally. Better understanding of the global burden and source attribution of salmonellosis will contribute to improved prevention strategies. This overview provides several insights and highlights opportunities for future studies. First, several approaches to attribution of salmonellosis to specific sources are available, and should be applied in more countries, according to the data sources available, to improve our knowledge of the epidemiology of this pathogen globally. The results of this overview suggest that all approaches can provide important information regarding the sources of pathogens that contribute the greatest burden of illness. Secondly, future studies of salmonellosis should attempt to identify countries or regions of the world where travel may be most associated with risk of Salmonella infection. This knowledge, coupled with the results of microbial subtyping studies or outbreak investigations exploring imported food sources of Salmonella, may be useful to prevention efforts targeting imported foods. Finally, food product surveillance systems may increase sampling of plant commodities, so that attribution approaches including these sources may be expanded beyond outbreak data. Limited data in the United States (USDA, 2012) suggest that contamination rates are relatively low in most of these foods. Rates likely vary among countries with different agricultural practices, and even a low rate in a commonly consumed food that is not cooked can be important.

\section{Acknowledgments}

We would like to thank Patricia M. Griffin for input that improved the content and clarity of this article.

\section{Disclosure Statement}

No competing financial interests exist.

\section{References}

Anonymous. Annual Report on Zoonoses in Denmark 2010. Copenhagen, Denmark: National Food Institute, Technical University of Denmark, 2011.

Cressey P, Lake R. Ranking food safety risks. Development of NZFSA policy 2004-2005. ESR Client Report FW0563. Christchurch, New Zealand: Institute of Environmental Science and Research Limited (ESR), 2005.

David JM, Sandersa P, Bemrahe N, Granierf SA, Denisg M, Weillh FX, Guillemotb D, Watierb L. Attribution of the French human Salmonellosis cases to the main food-sources according to the type of surveillance data. Prev Vet Med 2013;110:12-27.

Davidson VJ, Ravel A, Nguyen TN, Fazil A, Ruzante JM. Food-specific attribution of selected gastrointestinal illnesses: Estimates from a Canadian expert elicitation survey. Foodborne Pathog Dis 2011;8:983-995.

Domingues AR, Pires SM, Halasa T, Hald T. Source attribution of human salmonellosis using a meta-analysis of case-control studies of sporadic infections. Epidemiol Infect 2012;140:970 981.

Ekdahl K, De Jong B, Wollin R, Andersson Y. Travel-associated non-typhoidal salmonellosis: Geographical and seasonal differences and serotype distribution. Clin Microbiol Infect 2005;11:138-144.
[EFSA] European Food Safety Authority. Scientific Opinion of the Panel on Biological Hazards on a request from EFSA on overview of methods for source attribution for human illness from food borne microbiological hazards. EFSA J 2008;764:1-43.

Gould LH, Walsh K, Vieira AR, Herman K, Williams IT, Hall AJ, Cole D. Surveillance for foodborne disease outbreaks-United States, 1998-2008. MMWR Surv Summary 2013;62:1-34.

Greenland S, Robins JM. Conceptual problems in the definition and interpretation of attributable fractions. Am J Epidemiol 1998;128:1185-1197.

Guo C, Hoekstra RB, Schroeder CM, Pires SM, Ong KL, Hartnett E, Naugle A, Harman J, Bennett P, Cieslak P, Scallan E, Rose B, Holt KG, Kissler B, Mbandi E, Roodsari $\mathrm{R}$, Angulo FJ, Cole D. Application of Bayesian techniques to model the burden of human salmonellosis attributable to US food commodities at the point of processing: Adaptation of a Danish model. Foodborne Pathog Dis 2011;8:509-516.

Hald T, Vose D, Wegener HC, Koupeev T. A Bayesian approach to quantify the contribution of animal-food sources to human salmonellosis. Risk Anal 2004;24:255-269.

Hall G, Kirk M. Foodborne illness in Australia. Annual incidence circa 2000. Canberra: Australian Government Department of Health and Aging, 2005.

Hall AJ, Wikswo ME, Manikonda K, Roberts VA, Yoder JS, Gould LH. Acute gastroenteritis surveillance through the National Outbreak Reporting System, United States. Emerg Infect Dis 2013;19:1305-1309.

Havelaar AH, Galindo AV, Kurowicka D, Cooke RM. Attribution of foodborne pathogens using structured expert elicitation. Foodborne Pathog Dis 2008;5:649-659.

Havelaar AH, Ivarsson S, Löfdahl M, Nauta, MJ. Estimating the true incidence of campylobacteriosis and salmonellosis in the European Union, 2009. Epidemiol Infect 2012;141:293-302.

Hoffmann S, Fischbeck P, Krupnick A, McWilliams M. Using expert elicitation to link foodborne illnesses in the United States to foods. J Food Prot 2007;70:1220-1229.

Kendall ME, Crim S, Fullerton K, Han PV, Cronquist AB, Shiferaw B, Ingram LA, Rounds J, Mintz ED, Mahon BE. Travel-associated enteric infections diagnosed after return to the United States, Foodborne Diseases Active Surveillance Network (FoodNet), 2004-2009. CID 2012;54:480-487.

King N, Lake R, Campbell D. Source attribution of nontyphoid salmonellosis in New Zealand using outbreak surveillance data. J Food Prot 2011;74:438-445.

Lake RJ, Cressey PJ, Campbell DM, et al. Risk ranking for foodborne microbial hazards in New Zealand: Burden of disease estimates. Risk Anal 2010;30:743-752.

Levine B. What does the population attributable fraction mean? Preventing Chronic Disease. 2007. Available at: www.cdc.gov/ pcd/issues/2007/jan/pdf/06_0091.pdf, accessed May 15, 2013.

Mead PS, Slutsker L, Dietz V, McCaig LF, Bresee JS, Shapiro C, Griffin PM, Tauxe RV. Food-related illness and death in the United States. Emerg Infect Dis 1999;5:607-625.

Mullner P, Jones G, Noble A, Spencer SE, Hathaway S, French NP. Source attribution of food-borne zoonoses in New Zealand: A modified Hald model. Risk Analysis 2009;29:970-984.

O'Brien S. The "decline and fall" of nontyphoidal Salmonella in the United Kingdom. Clin Infect Dis 2013;56:705-710.

Painter J. Estimating attribution of illnesses to food vehicle from reports of foodborne outbreak investigations. Society for Risk Analysis 2006 Annual Meeting, Baltimore, MD, December 3-6, 2006.

Painter JA, Hoekstra RM, Ayers T, Tauxe RV, Braden CR, Angulo FJ, et al. Attribution of foodborne illnesses, hospitalizations, and 
deaths to food commodities by using outbreak data, United States, 1998-2008. Emerg Infect Dis 2013;19:407-415.

Pires SM, Evers EG, van Pelt W, Ayers T, Scallan E, Angulo FJ, Havelaar A, Hald T. Attributing the human disease burden of foodborne infections to specific sources. Foodborne Pathog Dis 2009;6:417-424.

Pires SM. Attributing human salmonellosis and campylobacteriosis to animal, food and environmental sources. $\mathrm{PhD}$ Thesis. Faculty of Life Sciences, University of Copenhagen, Denmark, 2009.

Pires SM, Vigre H, Makela P, Hald T. Using outbreak data for source attribution of human salmonellosis and campylobacteriosis in Europe. Foodborne Pathog Dis 2010;7:1351-1361.

Pires SM, de Knegt L, Hald T. Estimation of the relative contribution of different food and animal sources to human Salmonella infections in the European Union. 2011a. Available at: http:// www.efsa.europa.eu/en/supporting/doc/184e.htmhttp://www .efsa.europa.eu/en/supporting/doc/184e.htm.

Pires SM, Toyofuku H, Kasuga F, Hald T. Attributing foodborne disease in Japan using outbreak data. Presented at: International Association for Food Protection Annual Meeting, Milwaukee, Wisconsin, August July 31-August 3, 2011b.

Pires SM, Vieira A, Perez E, Wong DLF, Hald T. Attributing human foodborne illness to food sources and water in Latin America and the Caribbean using data from outbreak investigations. Int J Food Microbiol 2012;152:129-138.

Pires SM. Assessing the applicability of currently available methods for attributing foodborne disease to sources, including food and food commodities. Foodborne Pathog Dis 2013;10:206-213.

Ravel A, Greig J, Tinga C, Todd E, Campbell G, Cassidy M, Marshall B, Pollari F. Exploring historical Canadian foodborne outbreak data sets for human illness attribution. J Food Prot 2009;72:1963-1976.

Ravel A, Davidson VJ, Ruzante JM, Fazil A. Foodborne proportion of gastrointestinal illness: Estimates from a Canadian expert elicitation survey. Foodborne Pathog Dis 2010;7:14631472.

Scallan E, Jones TF, Cronquist A, Thomas S, Frenzen P, Hoefer D, Medus C, Angulo FJ and the FoodNet Working Group.
Factors associated with seeking medical care and submitting a stool sample in estimating the burden of foodborne illness. Foodborne Pathog Dis 2006;3:432-438.

Scallan E, Hoekstra RM, Angulo FJ, Tauxe RV, Widdowson M-A, Roy SL, et al. Foodborne illness acquired in the United States-Major pathogens. Emerg Infect Dis 2011;17:7-15.

Toyofuku H, Hald T. Salmonella source attribution in Japan by a microbiological subtyping approach. EcoHealth 2011;7(Suppl 1): S22-S23.

[USDA] U.S. Department of Agriculture. Agricultural Marketing Service Microbiological Data Program. 2012. Available at: http://www.ams.usda.gov/AMSv1.0/ams.fetchTemplateData .do? template $=$ TemplateO\&topNav $=\&$ leftNav $=$ Scienceand Laboratories\&page $=$ MDPProgramReports\&description $=$ $\mathrm{MDP}+$ Program + Reports\&acct $=$ microbiodataprg, accessed June 10, 2013.

Valkenburgh S, Oosterom R, Van Stenvers O, Aalten M, Braks M, Schimmer B, Giessen A, Van Pelt W, Langelaar M. Zoonoses and zoonotic agents in humans, food, animals and feed in the Netherlands 2003-2006. RIVM rapportnummer: 330152001. Bilthoven, the Netherlands: National Institute for Public Health and the Environment, 2007.

Wegener HC, Hald T, Lo Fo WD, Madsen M, Korsgaard H, Bager F, Gerner-Smidt P, Molbak K. Salmonella control programs in Denmark. Emerg Infect Dis 2003;9:774-780.

Wegener H. Danish initiatives to improve the safety of meat products. Meat Sci 2010;84:276-283.

Whalström H, Andersson Y, Plym-Forshell L, Pires SM. Source attribution of human Salmonella cases in Sweden. Epidemiol Infect 2011;139:1246-1253.

Address correspondence to: Sara M. Pires, DVM National Food Institute Technical University of Denmark Morkhøj Bygade 19 Sфborg 2860, Denmark

E-mail: smpi@food.dtu.dk 